\title{
Knowledge, Attitude, and Practices towards Malaria among Employees from Enterprises in the Town of Douala, Cameroon
}

\author{
Christian Mbohou Nchetnkou $\left(\mathbb{D},{ }^{1}\right.$ Loick Pradel Kojom Foko $\left(\mathbb{D},{ }^{1}\right.$ \\ and Leopold Gustave Lehman iD ${ }^{1,2}$ \\ ${ }^{1}$ Department of Animal Organisms, Faculty of Science, The University of Douala, P.O. Box 24157, Douala, Cameroon \\ ${ }^{2}$ Department of Biological Sciences, Faculty of Medicine and Pharmaceutical Sciences, The University of Douala, P.O. Box 24157, \\ Douala, Cameroon
}

Correspondence should be addressed to Leopold Gustave Lehman; leopoldlehman@gmail.com

Received 17 January 2020; Accepted 6 May 2020; Published 26 June 2020

Academic Editor: Gilbert Lefèvre

Copyright (c) 2020 Christian Mbohou Nchetnkou et al. This is an open access article distributed under the Creative Commons Attribution License, which permits unrestricted use, distribution, and reproduction in any medium, provided the original work is properly cited.

\begin{abstract}
Background. Malaria remains a public health issue in the world especially in resource-limited countries, where it has a negative impact on their economy. There is a body of recent reports outlining the crucial role of enterprises in control of malaria. The present study aimed at determining the knowledge, attitudes, and practices (KAP) towards malaria among employees from enterprises in the town of Douala, Cameroon. Methods. A cross-sectional descriptive study took place between February 2015 and June 2017 in 14 enterprises of Douala. A pretested structured questionnaire was used to document sociodemographic parameters and KAP of employees. Results. A total of 2705 employees, mainly consisted of males (83.1\%), were included in the study. The mean age of respondents was $37.33 \pm 9.78$ years (range 19-87). Over $90 \%$ of respondents knew at least one sign/symptom (94.1\%) and associated malaria transmission with mosquito bites (91\%). Artemether-Lumefantrine (36.2\%), under commercial name "Coartem," was the most cited antimalarial drug. Nearly $98.2 \%$ considered malaria as a dangerous disease. Misconceptions on malaria transmission, causative agent, prevention, and treatment were recorded. More than $77 \%$ of employees declared to use mosquito bed nets to prevent malaria. About 63\% employees declared going to the hospital when they were feel having malaria while $12.9 \%$ were seeking care through street drugs. Educational level, socioprofessional category, area of residence, and enterprise were significantly associated with the level of knowledge on malaria transmission, causative agent, and preventive and treatment practices. Conclusion. This study showed a good level of knowledge, attitudes, and practices of employees even though some misconceptions and bad behaviors are still present especially in people with a low level of education. Hence, there is a need to develop strategies for sensitization especially in this fraction of employees. In addition, enterprises could be an interesting approach in order to control malaria in Cameroon.
\end{abstract}

\section{Introduction}

Malaria remains a major public health concern across the world. According to the World Health Organization (WHO), an estimated 228 million cases of malaria and 405,000 deaths occurred worldwide in 2018 [1]. SubSaharan Africa (SSA) alone accounted for $93 \%$ of cases and $94 \%$ of deaths. In Cameroon, malaria is the first cause of consultation (26\%) and hospitalization (46\%); it is responsible for $22 \%$ of annual deaths [2].
Malaria has a negative impact in many sectors, including education [3], agriculture [4, 5], and business [6]. Roll Back Malaria (RBM) consortium reported that malaria has negative effect on enterprises in SSA [7]. Malaria negatively impacts enterprises. It causes a decrease in productivity and investments due to both increased employee absenteeism and health care expenditures [7]. Previous studies in Equatorial Guinea, Zambia, Ghana, have revealed that enterprises could play an important role in the reduction of malaria incidence through the integration and implementation of malaria control strat- 
TABLE 1: Enterprises distributed by branch of activity and codes.

\begin{tabular}{lcr}
\hline Branch of activity & Code of enterprises & Location \\
\hline Cocoa and coffee export & ENT 1 & Douala 1 \\
Security & ENT 2, ENT 5, ENT 7 & Douala 1 \\
Electricity & ENT 3 & Douala 1 \\
Food processing & ENT 4 & Douala 3 \\
Employment agency & ENT 6 1 \\
Hydraulic and drilling & ENT 8 & Douala 1 \\
Public hygiene and sanitation & ENT 9 & Douala 3 \\
Hotel & ENT 10 & Douala 1 \\
Construction and public works & ENT 11 & Douala 3 \\
Manufacturing and selling mattresses and foam & ENT 12 & Douala 3 \\
Distribution of petroleum products & ENT 13 & Douala 1 \\
Car dealership & ENT 14 & Douala 3 \\
\hline
\end{tabular}

egies in their management policies [7, 8]. These strategies include the distribution of long-lasting insecticide-treated nets (LLINs), insecticide residual spraying (IRS) campaigns, and the implementation of rapid malaria diagnosis. The implementation of the above-mentioned control strategies has resulted in significant reduction in malaria burden not only in employees but also in communities in which the enterprises are installed [7].

Malaria control is changing in several endemic countries where community/individuals adhesion to control and prevention measures is placed at the core of control policies, with a growing interest in health education through the understanding of knowledge, attitudes, and practices (KAP) towards malaria and its control [9]. KAP studies are also essential in establishing epidemiological and behavioral baselines in monitoring programs against malaria [9]. In fact, a person who has poor KAP towards a given disease may probably be reluctant to use some of the preventive measures and communicate the information on their positive effects on the control of the disease. Furthermore, this person may get involved in poor practices such as self-medication and improper use of LLINs $[3,10]$; they could transmit their misconceptions to relatives. It is therefore critical to monitor the knowledge, attitudes, and practices of the population towards malaria.

A recent study on malaria in some enterprises in Cameroon revealed $30.1 \%$ prevalence of the infection among employees [11]. Given the magnitude of the disease and its potential negative impact on businesses [12], enterprises should better commit in malaria prevention and control $[13,14]$. Investigating KAP of employees would generate evidence for the development of malaria control and prevention strategies of their employees.

This study was conducted in companies with the aim of generating evidence that would serve as a basis for the development and revision of control strategies, adapted to the enterprises and communities that host them.

\section{Materials and Methods}

2.1. Type and Study Site. The study was conducted in Douala (Cameroon), the economic capital city of the country, accounting for $33.5 \%$ of enterprises [15]. Fourteen enter- prises are from 12 sectors of activity, having their headquarters in Douala. Douala has a warm and humid climate with a mean temperature of $\sim 26^{\circ} \mathrm{C}$ and heavy rainfall, especially during the rainy season that goes from June to October [16]. This climate is conducive to the development of mosquitoes, thus to malaria transmission [17]. These two reasons have guided the choice of Douala for the study. In order to preserve the reputation of these enterprises, they were assigned; so their names are not disclosed (Table 1).

This cross-sectional study was conducted between February 2015 and June 2017. Prior to interviews, officials of each enterprise were met and given clear explanation of the aims of the study. After authorization from the management, dates were set for interviews and the communication unit was charged with disseminating the information to employees. Only employees who gave written inform consent were enrolled in the study. A pretested structured questionnaire was used to document the answers from respondent.

2.2. Study Population and Eligibility Criteria. The study population was made up of employees. Inclusion criteria were (i) being an employee of the enterprise and (ii) having signed an informed consent form (Additional file 1). Conversely, any participant who did not meet up with at least one of the above-mentioned criteria was excluded from the study.

2.3. Determination of Sample Size. The sample size was determined using Lorentz's formula as follows: $N=p *(1-p) *$ $Z^{2} / d^{2}$, where $N$ is the estimated minimum sample size, $p$ is the proportion of employees having a good level of knowledge on malaria, $Z$ is the statistic for desired level of confidence ( 1.96 for $95 \%$ confidence level), and $d$ is the accepted margin of error (5\%). Due to the absence of data on KAP studies among employees in Cameroon, a level of knowledge of $50 \%$ was assumed; thus, the minimum sample size was 384. In total, 2705 employees were included in the study.

2.4. Collection of Data of Interest. Data were collected using a structured questionnaire (Additional file 2). The first part of the questionnaire was about demographic variables which included age, gender, area of residence, level of education, 
TABLe 2: Demographic characteristics of the participants with respect to study enterprises.

\begin{tabular}{|c|c|c|c|}
\hline Characteristics & Categories & Total $(n=2705)$ & $P$ value \\
\hline \multirow{2}{*}{ Gender } & Female & $458(16.9)$ & \multirow[t]{2}{*}{$<0.001^{*}$} \\
\hline & Male & $2247(83.1)$ & \\
\hline \multirow{3}{*}{ Age (years) } & $19-36$ & $1307(48.3)$ & \multirow{3}{*}{$0.012^{*}$} \\
\hline & $36-60$ & $1351(50.0)$ & \\
\hline & $\geq 60$ & $47(1.7)$ & \\
\hline \multirow{5}{*}{ Level of education } & None/primary & $456(16.9)$ & \multirow{5}{*}{$<0.001^{*}$} \\
\hline & Lower secondary & $656(24.3)$ & \\
\hline & Upper secondary & $769(28.4)$ & \\
\hline & Bachelor's degree & $505(18.6)$ & \\
\hline & Master's degree and above & $319(11.8)$ & \\
\hline \multirow{3}{*}{ Professional category } & Workers & $2176(80.4)$ & \multirow{3}{*}{$<0.001^{*}$} \\
\hline & Agent-control & $463(17.2)$ & \\
\hline & Managers & $66(2.4)$ & \\
\hline \multirow{2}{*}{ Work time } & Day & $1522(56.3)$ & \multirow[t]{2}{*}{$<0.001^{*}$} \\
\hline & Night & $1183(43.7)$ & \\
\hline \multirow{6}{*}{ Residence } & Douala 1 & $325(12.2)$ & \multirow{6}{*}{$<0.001^{*}$} \\
\hline & Douala 2 & $221(8.3)$ & \\
\hline & Douala 3 & $1345(50.6)$ & \\
\hline & Douala 4 & $174(6.5)$ & \\
\hline & Douala 5 & $568(21.4)$ & \\
\hline & Outside Douala & $27(1.0)$ & \\
\hline \multirow{4}{*}{ Household size ${ }^{\#}$} & $\leq 2$ & $546(20.6)$ & \multirow{4}{*}{$0.048^{*}$} \\
\hline & $3-4$ & $761(28.7)$ & \\
\hline & $5-6$ & $735(27.7)$ & \\
\hline & $\geq 7$ & $612(23.0)$ & \\
\hline
\end{tabular}

Data are presented as frequency (percentage). ENT: enterprise. ${ }^{*}$ Missing data. The goodness-of-fit chi-square test was used to compare proportions. ${ }^{*}$ Significant at $P<0.05$.

enterprises, and professional category. The second part was designed to capture knowledge, attitudes, and practices towards malaria including recognition of signs and symptoms, transmission, pathogen, prevention, treatment and management, perception of malaria, and date of last malaria attack. The questionnaire was written in the two official languages (French and English) (Additional file 2). To insure its reliability and eliminate bias of understanding, the questionnaire was pretested on 15 randomly chosen individuals and updated accordingly before data collection. Interviewers were trained on all aspects of data collection. Each interview lasted 15 to 20 minutes. The participants were informed on the importance of answering questions honestly. The principal investigator supervised data collectors on a daily basis, and the filled forms were scrutinized thoroughly every day.

2.5. Ethical Considerations. Ethical clearance was issued by the Institutional Review Board (IRB) of the University of Douala (under No. CE218 DU/268/05/2019/T). Further authorizations were obtained from the management of enterprises. The study was carried in accordance with guidelines for human experimental models in clinical research as stated by the Cameroon Ministry of Public Health. The aim of the study was clearly explained to employees in order to get their informed consent; employees who did not consent to participate were excluded from the study. Confidentiality of personal information was insured throughout the study. After interviews, employees were educated on malaria prevention and control based on their misconceptions.

2.6. Statistical Analysis. All data were keyed into an Excel spreadsheet and then analyzed with the statistical package for social science (SPSS) version 16 for Windows (SPSS Inc., Chicago, IL, USA). Goodness-of-fit, chi-square independence $\left(\chi^{2}\right)$ and Fisher's exact tests were used to compare proportions. Univariate and multivariate logistic regression models were used to identify factors associated with knowledge of malaria namely mode of transmission, causative agent, and use of paracetamol as antimalarial drug. Multimodal regression was used to identify the factors associated with the utilization of at least one preventive method. Odds ratios (OR) and 95\% confidence intervals (95\% CI) were also computed. Statistical significance was set at $P<0.05$. 


\section{Results}

3.1. Sociodemographic Characteristics of the Employees. Sociodemographic information of respondents are presented in Table 2. Most of the respondents were male (83.1\%). Half of the participants were aged 36-59 years old (50.0\%), and a statistically significant difference was found in proportions of different age groups $(p=0.012)$. The mean age of respondents was $37.33 \pm 9.78$ years old (range 19-87). Based on the level of education, respondents having completed who completed upper secondary were the most represented $(28.4 \%)$ while $11.9 \%$ of respondents were holders of master degrees or equivalent and above. Employees were mainly workers $(80.4 \%)$ while $2.4 \%$ were managers. Slightly above half of the respondents, 1345 (50.6\%) were living in the third district of Douala. $28.7 \%$ of interviewees were living in households with 3-4 members (Table 2).

\subsection{Knowledge on Malaria}

3.2.1. Signs and Symptoms. The employees' responses to questions on malaria signs and symptoms and route of transmission are summarized in Table 3. More than $90 \%$ of employees knew at least one sign or symptom of malaria. Fever was the most cited sign $(n=1750,64.7 \%)$ followed by headache $(39.1 \%)$, body pain $(31.9 \%)$, and chills $(22.8 \%)$.

3.2.2. Routes of Transmission. The majority of employees interviewed $(90.7 \%, n=2452)$ knew that mosquitoes were responsible for malaria transmission. Others (9.3\%) gave wrong answers as they attributed malaria transmission to various factors (bite of phlebotomy, consumption of dirty water, cold weather, lack of sport exercise, and consumption of sugar).

3.3. Causative Agent. Less than one in ten respondents ( $n=255,9.4 \%$ ) knew that Plasmodium falciparum is the pathogen responsible for malaria infection. However, wrong answers (8.91\%) were recorded, namely, Entamoeba histolytica, mosquitoes, Anopheles mosquitoes, flies (Glossina palpalis), insects, insalubrity, and consumption of dirty fruits/water.

3.3.1. Drugs for the Treatment of Malaria. More than half of the participants knew the name of at least one antimalarial drug $(52.0 \%, n=2705)$. The most cited malaria drugs were Artemether-Lumefantrine (Coartem ${ }^{\circledR}$ ) and quinine with $36.2 \%$ and $23.8 \%$ citation frequencies, respectively (Figure 1). Paracetamol was cited by 914 (33.9\%) respondents.

3.4. Date of Last Malaria Attack. Sixteen percent of employees got their last malaria attack less than a month ago. The others reported last malaria attack 1-6 months (28.9\%), 7-11 months (18.9\%), or $\geq 12$ months (25.3\%) ago. It should be noted that $2.1 \%$ employees said they never had malaria.

3.5. Attitudes towards Malaria. Almost all (98.2\%) respondents agreed with the fact that malaria is a dangerous disease, and the main reasons were that "it kills" $(86.2 \%)$, "it causes
TABLE 3: Respondents' knowledge on signs and symptoms of malaria.

\begin{tabular}{lcc}
\hline Answers & Frequency & Percentage (\%) \\
\hline Number of symptoms cited & & \\
0 & 159 & 5.9 \\
1 & 793 & 29.4 \\
2 & 1147 & 42.5 \\
3 & 516 & 19.1 \\
4 & 77 & 2.9 \\
5 & 9 & 0.3 \\
Symptoms cited & & \\
Fever & 1750 & 64.7 \\
Headache & 1058 & 39.1 \\
Body pain & 864 & 31.9 \\
Chills & 617 & 22.8 \\
Fatigue & 539 & 19.9 \\
Poor appetite & 505 & 18.7 \\
\hline
\end{tabular}

${ }^{*}$ Frequency is more than the total number of employees (2705) as an employee who can give more than one answer.

anemia" (1.04\%), and "it decreases productivity" (0.3\%). Other reasons such as "it is the cause of absenteeism" $(0.0005 \%)$ and "it weakens the body" $(0.006 \%)$ were also reported.

3.6. Malaria Prevention Methods Used by the Respondents. Eight preventive methods were reported by the respondents. The most reported were ITNs, IRS, and environmental sanitation (Additional file 3). The majority of respondents (57\%) used one preventive method only while the rest used two (30.1\%), three $(4.8 \%)$, and four $(0.4 \%)$ methods. The combinations ITN+IRS (8.4\%) and ITN+long-sleeved clothes $(8.5 \%)$ were the most reported by those using two preventive methods (Additional file 3).

3.7. Management of Malaria Cases by Employees'. Sixty-three percent of respondents declared going to hospital when they feel having malaria (Table 4). The rest of employees declared mainly managing malaria by buying drugs from pharmacy $(26.3 \%)$ and street vendors 338 (12.9\%). To be noted, a small fraction of interviewees were resorting to traditional medicine (8.6\%, Table 4$)$. The reason for buying drugs from street vendors was mainly associated with price difference between drugs from pharmacy and those from street vendors.

3.8. Association between Sociodemographic Factors and Knowledge of Malaria. Level of education, socioprofessional category, and enterprise were significantly associated with the knowledge on the causative agent of malaria. Employees having completed lower and upper secondary education were nearly 4 times $(\mathrm{OR}=3.51, P<0.0001)$ and 8 times $(\mathrm{OR}=7.59, P<0.0001)$ more knowledgeable on the causative agent of malaria compared with those with no formal studies or with primary education only (Tables 5 and 6). In addition, the level of knowledge was 


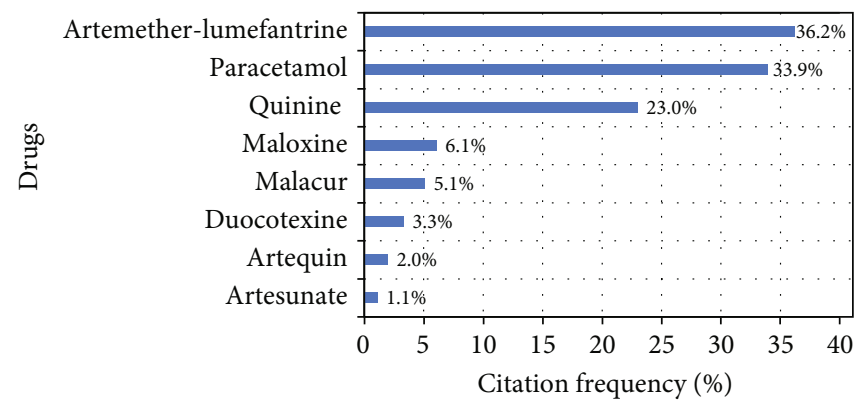

FIgURE 1: Answers of participants about drugs used for treating malaria episodes.

TABle 4: Home management of malaria cases by employee's households.

\begin{tabular}{lcc}
\hline Responses & Citation frequency & Percentage (\%) \\
\hline Hospital & 1624 & 63.0 \\
Pharmacy & 690 & 26.3 \\
Street drugs & 338 & 12.9 \\
Plants (traditional medicine) & 225 & 8.6 \\
Hospital and pharmacy & 170 & 6.5 \\
Hospital and street drugs & 41 & 1.6 \\
Pharmacy and street drugs & 41 & 1.6 \\
\hline
\end{tabular}

14 times higher $(\mathrm{OR}=14.30, P<0.0001)$ in those holding bachelor's degree and 13 times $(\mathrm{OR}=12.81, P<0.0001)$ higher in those holding master's degree or above. Besides, managers were more knowledgeable than laborers $(\mathrm{OR}=1.46, P=0.039)$ while employees from enterprises 4 and 6 were more knowledgeable on the causative agent than those from enterprise $1(\mathrm{OR}=4.06, P=0.004$, and $\mathrm{OR}=3.49, P=0.017$, respectively).

Three variables were also significantly associated with knowledge on malaria transmission (Tables 5 and 6). Employees with no formal studies/primary level of education were less knowledgeable on malaria transmission than those having completed secondary and university studies. For instance, holders of bachelor's or master' degree and above were, respectively, nearly 4 times $(\mathrm{OR}=3.77,95 \%$ CI 2.13 $6.70, P<0.0001)$ and 6 times $(\mathrm{OR}=6.42$, 95\% CI 2.60 15.90, $P<0.0001)$ more knowledgeable on the route of malaria transmission than those having no formal studies or competed primary studies. Respondents from the Douala 3 District were 1.63 times more knowledgeable on malaria transmission than those from Douala 1 (OR $=1.63, P=$ 0.026). Regarding enterprises, employees from enterprises $7,10,11$, and 14 were more knowledgeable than those from enterprise $1(P=0.023, P=0.013, P=0.022$, and $P=0.017$, respectively; Tables 5 and 6 ).

The area of residence was the only factor associated with use of paracetamol as a single antimalarial drug. The risk of using paracetamol only as antimalarial drug was lesser in individuals living in the Douala 4 District $(\mathrm{OR}=0.50, P=0.016)$ than their counterparts living in Douala 1 District (Tables 5 and 6).

The level of education and socioprofessional category were significantly associated with the use of preventive methods as presented in Tables 5 and 6. Chances for using one preventive method were higher in employees having completed lower and upper secondary studies, respectively, as compared with those having completed primary or no formal studies $(\mathrm{OR}=1.63, P=0.027$, and $\mathrm{OR}=1.76, P=0.041$, respectively). Managers were about 3 times likely to use a preventive method compared with laborers $(\mathrm{OR}=2.92, P=0.026)$.

\section{Discussion}

Most of the respondents in this study (94.1\%) knew at least one symptom of malaria and $91 \%$ mentioned at least three symptoms. This high level of knowledge agrees with previous studies in Cameroon $[10,18]$. Douala is a setting of perennial transmission of malaria; thus, individuals living in this areas have likely faced a malaria episode at least once in their life $[10,16]$.

The knowledge of malaria causative agent was low (9.4\%). This result is in line with that from Kojom and Lehman [10] in Cameroon and Mazigo et al. [18] in Tanzania who found the level of knowledge of $14.3 \%$ and $6 \%$, respectively. During health campaigns and other sensitization activities, the malaria causative agent is usually not made mention of, focus being on the vector [10]. This can explain why many employees confused causative agent with malaria vector.

More than half of respondents (52\%) had good knowledge of treatment of malaria. ACTs were most reported, and this is consistent with previous studies in the country $[10,18]$. Cameroon has adopted ACTs in 2004 for the treatment of uncomplicated malaria [19]. Besides, one-third (33.9\%) of employees cited paracetamol for malaria treatment. This can be explained by the fact that this paracetamol is usually included in the package prescribed for the treatment [10]. Taking paracetamol as an antimalarial can result in the aggravation of malaria with complications such as kidney failure [10].

Nearly $17 \%$ of employees reported on a malaria episode less than a month ago, lower than a previous report from Burkina Faso (32\%) in 1988 [20]. The difference may be due to the fact that from 1988 to 2016 , great efforts have been made for malaria prevention and control, including sensitization and mass distribution of bed nets, resulting in lower prevalence of malaria. Besides, $70 \%$ of employees reported having at least one malaria attack in the past 12 months; 


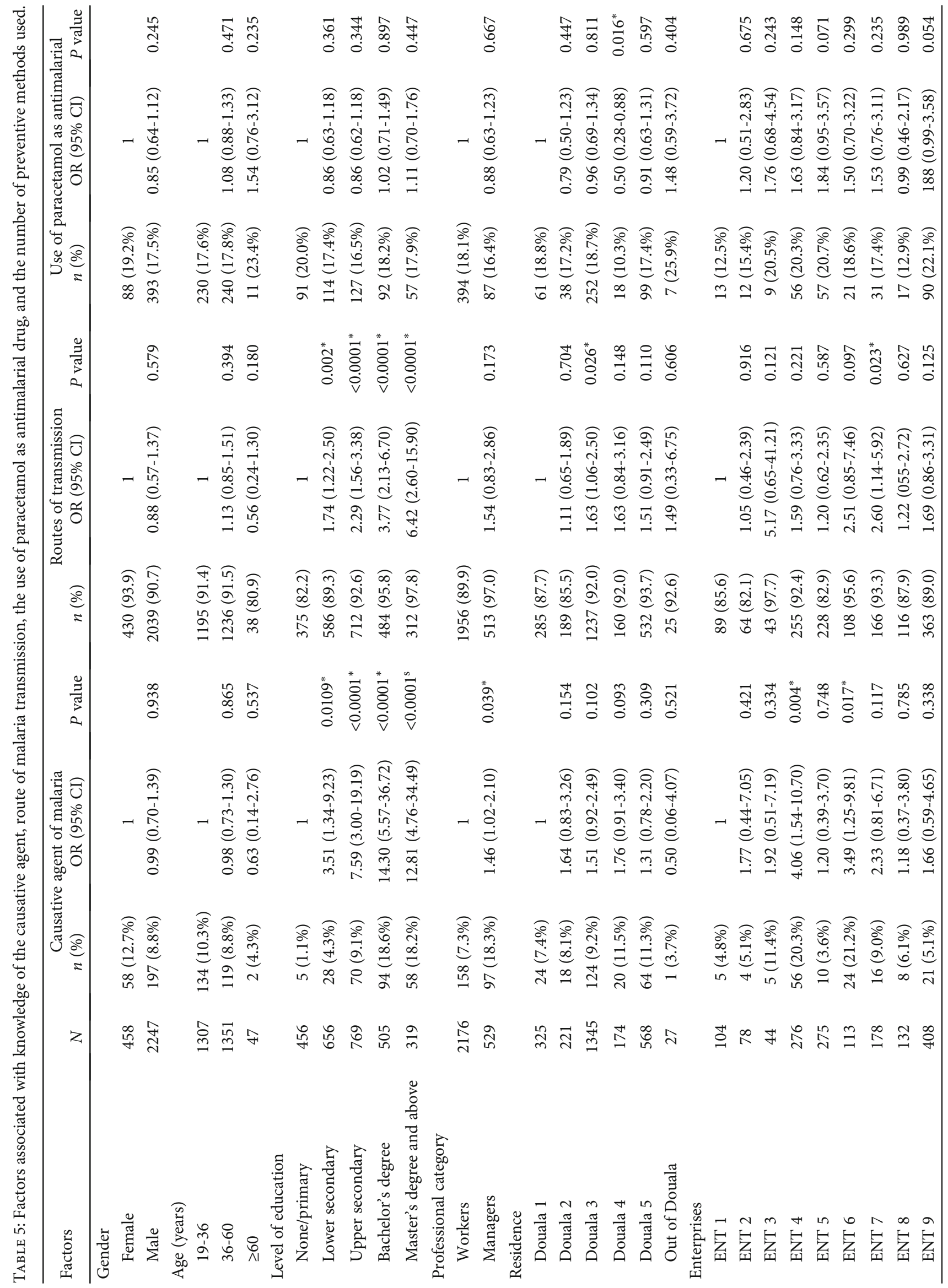




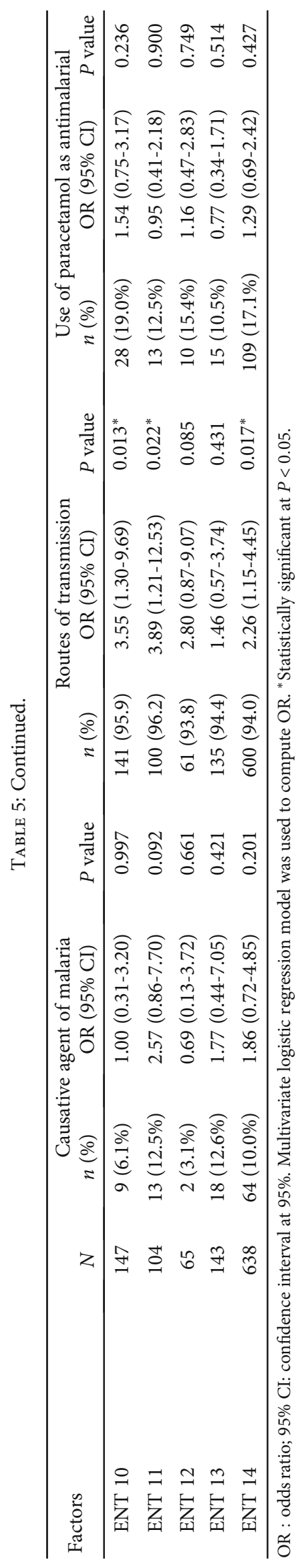


TABLE 6: Factors associated with the number of preventive methods used.

\begin{tabular}{|c|c|c|c|c|c|c|}
\hline \multirow[b]{2}{*}{ Factors } & \multicolumn{2}{|c|}{ One method used } & \multicolumn{2}{|c|}{ Two methods used } & \multicolumn{2}{|c|}{ Three methods used } \\
\hline & OR $(95 \% \mathrm{CI})$ & $P$ value & OR $(95 \% \mathrm{CI})$ & $P$ value & OR (95\% CI) & $P$ value \\
\hline \multicolumn{7}{|l|}{ Gender } \\
\hline Female & 1 & & 1 & & 1 & \\
\hline Male & $0.96(0.64-1.44)$ & 0.835 & $0.81(0.50-1.29)$ & 0.369 & $0.84(0.34-2.07)$ & 0.700 \\
\hline \multicolumn{7}{|l|}{ Age (years) } \\
\hline $19-36$ & 1 & & 1 & & 1 & \\
\hline $36-60$ & $0.95(0.71-1.28)$ & 0.741 & $1.01(0.72-1.43)$ & 0.941 & $1.24(0.60-2.54)$ & 0.558 \\
\hline$\geq 60$ & $2.18(0.51-9.34)$ & 0.294 & $2.54(0.52-12.48)$ & 0.251 & $2.68 \mathrm{E}-7(0.00-?)$ & 0.996 \\
\hline \multicolumn{7}{|l|}{ Level of education } \\
\hline None/primary & 1 & & 1 & & 1 & \\
\hline Lower secondary & $1.31(0.87-1.97)$ & 0.201 & $1.14(0.69-1.86)$ & 0.614 & $0.18(0.02-1.65)$ & 0.127 \\
\hline Upper secondary & $1.63(1.05-2.51)$ & $0.027^{*}$ & $1.56(0.94-2.60)$ & 0.087 & $2.24(0.67-7.55)$ & 0.191 \\
\hline Bachelor's degree & $1.76(1.02-3.08)$ & $0.041^{*}$ & $1.67(0.88-3.14)$ & 0.114 & $2.31(0.58-9.21)$ & 0.237 \\
\hline Master's degree and above & $1.22(0.64-2.34)$ & 0.542 & $1.36(0.64-2.89)$ & 0.427 & $1.01(0.20-5.06)$ & 0.991 \\
\hline \multicolumn{7}{|l|}{ Professional category } \\
\hline Workers & 1 & & 1 & & 1 & \\
\hline Managers & $1.14(0.69-1.88)$ & 0.597 & $1.37(0.78-2.41)$ & 0.227 & $2.92(1.13-7.54)$ & $0.026^{*}$ \\
\hline \multicolumn{7}{|l|}{ Residence } \\
\hline Douala 1 & 1 & & 1 & & 1 & \\
\hline Douala 2 & $0.68(0.38-1.20)$ & 0.187 & $1.37(0.78-2.41)$ & 0.277 & $0.18(0.02-1.66)$ & 0.131 \\
\hline Douala 3 & $1.11(0.69-1.78)$ & 0.669 & $0.70(0.35-1.40)$ & 0.319 & $1.33(0.47-3.76)$ & 0.587 \\
\hline Douala 4 & $1.03(0.52-2.05)$ & 0.929 & $1.10(0.63-1.90)$ & 0.742 & $0.24(0.03-2.24)$ & 0.211 \\
\hline Douala 5 & $0.97(0.58-1.64)$ & 0.897 & $1.33(0.61-2.89)$ & 0.473 & $0.53(0.16-1.75)$ & 0.301 \\
\hline Out of Douala & $0.63(0.17-2.34)$ & 0.494 & $0.70(0.38-1.27)$ & 0.238 & $8.78 \mathrm{E}-8(0.00-?)$ & 0.995 \\
\hline \multicolumn{7}{|l|}{ Enterprises } \\
\hline ENT 1 & 1 & & 1 & & 1 & \\
\hline ENT 2 & $0.93(0.36-2.43)$ & 0.885 & $0.53(0.16-1.75)$ & 0.297 & $1.31 \mathrm{E}-7(0.00-?)$ & 0.995 \\
\hline ENT 3 & $4.23(0.51-34.75)$ & 0.179 & $3.66(0.39-33.98)$ & 0.254 & $3.39(0.14-82.97)$ & 0.454 \\
\hline ENT 4 & $1.18(0.52-2.66)$ & 0.688 & $0.90(0.35-2.32)$ & 0.825 & $1.49(0.25-8.77)$ & 0.658 \\
\hline ENT 5 & $0.93(0.43-2.02)$ & 0.853 & $0.78(0.31-1.94)$ & 0.589 & $0.58(0.07-4.91)$ & 0.618 \\
\hline ENT 6 & $1.10(0.40-3.01)$ & 0.855 & $1.63(0.53-4.98)$ & 0.391 & $1.91(0.26-14.21)$ & 0.525 \\
\hline ENT 7 & $1.42(0.58-3.51)$ & 0.443 & $1.77(0.64-4.91)$ & 0.269 & $3.90(0.63-24.17)$ & 0.143 \\
\hline ENT 8 & $1.14(0.46-2.82)$ & 0.778 & $0.78(0.27-2.28)$ & 0.655 & $0.78(0.09-6.81)$ & 0.821 \\
\hline ENT 9 & $1.37(0.63-2.99)$ & 0.429 & $1.37(0.56-3.37)$ & 0.493 & $0.39(0.04-3.32)$ & 0.385 \\
\hline ENT 10 & $1.27(0.51-3.17)$ & 0.607 & $1.07(0.37-3.08)$ & 0.897 & $0.40(0.03-5.19)$ & 0.48 \\
\hline ENT 11 & $2.45(0.79-7.61)$ & 0.121 & $0.56(0.13-2.35)$ & 0.429 & 8.06E-8 (0.00-?) & 0.995 \\
\hline ENT 12 & $0.98(0.33-2.90)$ & 0.963 & $1.64(0.49-5.52)$ & 0.421 & $1.45 \mathrm{E}-7$ (0.00-?) & 0.994 \\
\hline ENT 13 & $0.97(0.40-2.36)$ & 0.955 & $0.48(0.16-1.41)$ & 0.181 & $0.63(0.08-4.72)$ & 0.651 \\
\hline ENT 14 & $1.67(0.78-3.54)$ & 0.183 & $0.88(0.37-2.13)$ & 0.784 & $0.86(0.15-4.94)$ & 0.869 \\
\hline
\end{tabular}

OR: odds ratio; $95 \%$ CI: confidence interval at $95 \%$. Multimodal logistic regression model was used to compute OR. ?: no value available. * Statistically significant at $P<0.05$.

Douala is located in a perennial transmission area with nearly 300 infective bites per man per year [21]. Thus, malaria transmission is high and the population exposed to multiple malaria episodes.

Malaria was perceived dangerous by most of the respondents $(98.2 \%)$ while $1.8 \%$ was somehow indifferent. This latter category may be at risk of suffering from severe malaria as they may not bother to prevent or seek for treatment on time
$[22,23]$. The level of awareness regarding signs and symptoms of malaria, as well as the perceived seriousness of the disease reported in this study, was higher than previously found in the Littoral and Southwest regions of Cameroon $[22,23]$. This could be probably due to the fact that people in malaria endemic areas are more likely to be more knowledgeable about disease and its consequences than those in malaria-free or low-endemic areas. 
Most of the respondents knew at least one malaria prevention method. Three preventive measures were mostly used by employees namely bed nets, insecticide spray, and environmental sanitation. This result is consistent with that of previous studies in the same setting [23]. ITNs are the main preventive methods used by respondents (77.23\%); this key tool for malaria control serves as physical and chemical barrier protecting users from infective mosquito bites [24]. The ITN use rate was higher than that of studies conducted in the Littoral and Centre regions [3, 25]. Conversely, this proportion is lower than that found in other Cameroonian studies and WHO-recommended target (80\%) [1, 11, 26]. This difference could be due to discrepancies in study design, study period, and population. In addition, these discrepancies could also be attributable to that fact employees received bed nets at work as a result of health promotion policies implemented in enterprises where they work as reported previously in Nigeria [9]. It is plausible that the true proportion of employees using ITNs could be lower than that estimated in the present study since a self-report-based approach was used to determine the rate of ITN use. In a recent meta-analysis, Krezanoski and colleagues showed that that approach had overestimated ITNs adherence by $>13 \%$ as compared to evidence-based approach [27].

However, the use of ITN insecticide spray and environmental sanitation do not guarantee a $100 \%$ protective effect especially against insecticide-resistant and/or outdoorbiting mosquitoes. Thus, it is crucial to associate complementary methods such as larval control and tracking of asymptomatic carriers of malaria parasites in order to efficiently control and/or eliminate malaria in a given area $[3,11]$. Previous studies in Tanzania have shown reduction in malaria transmission following the implementation of larval control interventions $[28,29]$.

Other employees were using traditional medicine (herbs and parts of plants), and this could be linked to sociocultural beliefs and practices [10,30]. To be noted, a fraction of employees said they go to pharmacy to seek for treatment. This was revealed in previous reports from the same areas, which also outlined the ease with which drugs could be obtained in pharmacies, without a medical prescription [3].

Besides, some employees were buying antimalarial treatment from street vendors. Previous studies in the Littoral and Northwest regions of Cameroon described the same phenomenon [23, 31]. The main reason given by respondents was their cheaper prices, compared with that of drugs available in hospital or pharmacy [32]. Street drugs are a major public health problem as many studies have shown the poor quality of these drugs, especially antimalarial, due to their questionable origin and poor storage conditions [33, 34]. There is also a concern about information given to their clients by vendors, regarding the type and dose of drugs [35]. Thus, the use of such drugs can increase the risk of complications in individuals resorting to street drugs and the appearance and spread of antimalarial drug resistance [10]. Artemether-Lumefantrine (AL) was the most cited antimalarial drug mainly under its commercial name Coartem ${ }^{\circledR}$; authors have reported poor quality Artemether-Lumefantrine (AL) 20/120 mg sold illegally in Cameroon [33].
Level of education was significantly associated with knowledge of malaria transmission and causative agent. Higher educational level significantly improved the knowledge of malaria transmission and causative agent. This can be explained by the fact that the more educated you are, the better you can access to knowledge and understand information on the disease [36]. This finding is in line with previous studies in the towns of Douala and Yaoundé $[10,34]$. The impact of education has also been demonstrated on the use of preventive method as the chances of using one preventive methods were higher in employees with higher levels of education.

It was also found that the chances for using three preventive methods were higher among managers compared to laborers. This could be due to income discrepancies between the two groups, managers having easier access to a variety of preventive methods.

\section{Conclusions}

This study revealed a high level of knowledge of signs and symptoms, mode of transmission, and drugs used for treating malaria among employees. They were aware of the dangers of malaria and used prevention methods, especially ITNs. However, some misconceptions and ill behavior still exist among them especially in those with a low level of education. Age, area of residence, socioprofessional category, and enterprises have significant influence on knowledge and practices of employees regarding malaria transmission, causative agent, and treatment and prevention practices. Hence, there is a need for developing sensitization strategies for employees, especially those with lower levels of education. Commitment of enterprises could foster malaria control in Cameroon.

\section{Abbreviations}

ACT: Artemisinin-based combination therapy

AL: $\quad$ Artemether-Lumefantrine

CCA/SIDA: Coalition de la Communauté des Affaires contre le SIDA, la tuberculose et le paludisme

CI: $\quad$ Confidence interval

IRB: Institutional Review Board

IRS: Indoor residual spraying

ITN: Insecticide-treated net

KAP: $\quad$ Knowledge, attitudes, and practices

LLINs: Long-lasting insecticide-treated nets

NGO: Nongovernment organization

OR: $\quad$ Odds ratio

RBM: $\quad$ Roll Back Malaria

SPSS: $\quad$ Statistical package for social sciences

URED: University-Research-DevelopmentEnvironment

WHO: World Health Organization.

\section{Data Availability}

All data generated or analyzed during this study are included in this published article. 


\section{Conflicts of Interest}

The authors declare that there is no conflict of interest regarding the publication of this paper.

\section{Authors' Contributions}

CNM, LPKF, and LGL conceived and designed the study. CNM and LPKF collected, analyzed, and interpreted the data. CNM drafted the first version of the manuscript with the help of LPKF. LPKF and LGL critically revised the manuscript for intellectual content. LGL supervised the work at all stages. All authors read and approved the final manuscript.

\section{Acknowledgments}

The authors are grateful to all the enterprise managers and staff for accepting that this study be carried out in their enterprises as well as all to employees who participated in this study. We thank the NGO CCA/SIDA (Coalition de la Communauté des Affaires contre le SIDA, la tuberculose et le paludisme) for their collaboration in data recording in those enterprises. The authors express their gratitude to the members of URED (University-Research-Development-Environment) research group for their technical assistance. We acknowledge the support of Mr. Godlove Wepnje Bunda from the University of Buea, Cameroon, and Dr. Calvin Tonga and Dr. Jerson Mekoulou Ndongo from the University of Douala, Cameroon, in proofreading and language editing the manuscript.

\section{Supplementary Materials}

Additional File 1: informed consent form (English and French versions). Additional File 2: questionnaire form used to document data of interest (English and French versions). Additional File 3: malaria preventive methods used by employees. (Supplementary Materials)

\section{References}

[1] WHO, World malaria report, The World Health Organization, Geneva, 2019, https://www.who.int/malaria/publications/ world-malaria-report-2019/report/fr/.

[2] MSP, Bulletin Epidémiologique annuel 2018 du Paludisme au Cameroun, Ministere de la santé publique du cameroun, 2018.

[3] L. Lehman, L. Foko, C. Tonga et al., "Epidemiology of malaria using LED fluorescence microscopy among schoolchildren in Douala, Cameroon," International Journal of Tropical Disease \& Health, vol. 29, no. 1, pp. 1-13, 2018.

[4] M. A. Bashirat, "Malaria incidence and crop productivity among farming households in Kabba/Bunnu," Journal of Agricultural Faculty of Gaziosmanpasa University, vol. 35, no. 2018-2, pp. 127-133, 2018.

[5] A. Aheisibwe, The Effect of Malaria on Agricultural Production in Uganda, Makerere University, 2008.

[6] C. Leighton and R. Foster, "Economic impacts of malaria in Kenya and Nigeria," in Research Paper 6, Health Financing and Sustainability Project, pp. 1-98, Health Financing and
Sustainability (HFS) Project. Abt Associates Inc., Prime Contractor, 1993, http://pdfs.semanticscholar.org/d8fe/ a95b227c935f1b15209596aed6021871a2ba.pdf?.

[7] RBM, Investissement des entreprises dans la lutte contre le paludisme: Retombées économiques et protection de la main d'œuvre en Afrique, Organisation Mondiale de la Santé, Genève, 2011, https://path.azureedge.net/media/documents/ MCP_rbm_pi_rpt_6_fr.pdf.

[8] P. Besnard, F. Foumane, J.-F. Foucher et al., "Impact of a new parasitologic laboratory for malaria diagnosis on diagnosis and cost of malaria in a company setting: experience from Angola," Médecine Tropicale, vol. 66, no. 3, pp. 269-272, 2006, [In French].

[9] V. Oluwasanmi Amusan, "Knowledge, attitudes and practices on malaria prevention and control among private security guards within Kaduna Metropolis, Kaduna State-Nigeria," Science Journal of Public Health, vol. 5, no. 3, pp. 240-245, 2017.

[10] L. P. Kojom Foko and L. G. Lehman, "Knowledge and beliefs towards malaria and associated factors among residents of the town of Douala, Cameroon," Archives of Current Research International, vol. 14, no. 3, pp. 1-17, 2018.

[11] C. N. Mbohou, L. P. K. Foko, H. N. Nyabeyeu et al., "Malaria screening at the workplace in Cameroon," PLoS One, vol. 14, no. 12, article e0225219, 2019.

[12] R. Chambon, P. Lemardeley, E. Latapie, and F. J. Louis, "Part of health costs related to malaria in a Cameroon enterprise," Médecine Tropicale, vol. 57, no. 2, pp. 169-173, 1997, [In French].

[13] V. Makoge, L. Vaandrager, H. Maat, and M. Koelen, "Poverty and health among CDC plantation labourers in Cameroon: perceptions, challenges and coping strategies," PLoS Neglected Tropical Diseases, vol. 14, article e0006100, 2017.

[14] R. Moyou-Somo, P. Essomba, E. Songue et al., "A public private partnership to fight against malaria along the ChadCameroon pipeline corridor: I. Baseline data on socioanthropological aspects, knowledge, attitudes and practices of the population concerning malaria," BMC Public Health, vol. 13, article 1023, 2013.

[15] INS, Recensement général des entreprises 2016 (rge-2) rapport préliminaire des principaux résultats, Institut National de la Statistique Cameroun, Cameroon, 2018, http://www.slmp550-104.slc.westdc.net/ stat54/downloads/2018/Projet_de_ rapport_preliminaire_RGE2_du_29_decembre_2017_final .pdf.

[16] MSP, Enquête Post campagne sur l'utilisation des Moustiquaires Imprégnées d'insecticide à Longue Durée d'Action 2016/2017, Ministère de la Santé Publique du Cameroun, 2017, http://www.slmp-550-104.slc.westdc.net/ stat54/ downloads/2018/Rapport_final_de_1_EPC-MILDA_20162017.pdf.

[17] MSP, Stratégie sectorielle de santé 2016-2027, Ministère de la Santé Publique du Cameroun, 2017, https://www.minsante .cm/site/?q=fr/content/strat\%C3\%A9gie-sectorielle-de-sant $\%$ C3\%A9-2016-2027-1.

[18] H. D. Mazigo, E. Obasy, W. Mauka et al., "Knowledge, attitudes, and practices about malaria and its control in rural northwest Tanzania," Malaria Research and Treatment, vol. 2010, Article ID 794261, 9 pages, 2010.

[19] WHO, WHO in Cameroon. Annual report 2016, World Health Organization, 2016, https://www.afro.who.int/publications/ who-cameroon-annual-report-2016. 
[20] P. Gazin, C. Freier, P. Turk, B. Gineste, and P. Carnevale, "Le paludisme chez les employés d'une entreprise industrielle africaine (Bobo Dioulasso, Burkina Faso)," Annales de la Société Belge de Médecine Tropicale, vol. 68, pp. 1-8, 1988.

[21] P. N. Akono, G. R. J. Tcheugoue, J. A. Mbida, C. Tonga, and L. G. Lehman, "Higher mosquito aggressiveness and malaria transmission following the distribution of alphacypermethrin impregnated mosquito nets in a district of Douala, Cameroon," African Entomology, vol. 26, no. 2, pp. 429-436, 2018.

[22] H. K. Kimbi, S. B. Nkesa, J. L. Ndamukong-Nyanga, I. U. N. Sumbele, J. Atashili, and M. B. S. Atanga, "Knowledge and perceptions towards malaria prevention among vulnerable groups in the Buea Health District, Cameroon," BMC Public Health, vol. 14, no. 1, p. 883, 2014.

[23] L. P. F. Kojom, N. A. Antoinette, T. Calvin, N. N. Hervé, M. N. Jerson, and L. L. Gustave, "Prevalence, patterns and factors associated with malaria self-medication among mothers of underfives in Douala, Cameroon," Biosciences of Cameroon, vol. 2, 2017.

[24] T. O. Apinjoh, J. K. Anchang-Kimbi, R. N. Mugri et al., "The effect of insecticide treated nets (ITNs) on Plasmodium falciparum infection in rural and semi-urban communities in the South West Region of Cameroon," PLoS One, vol. 10, no. 2, article e0116300, 2015.

[25] V. H. M. Tchinda, A. Socpa, A. A. Keundo et al., "Factors associated to bed net use in Cameroon: a retrospective study in Mfou health district in the Centre Region," Pan African Medical Journal., vol. 10, no. 1, 2012.

[26] C. Ndo, B. Menze-Djantio, and C. Antonio-Nkondjio, "Awareness, attitudes and prevention of malaria in the cities of Douala and Yaoundé (Cameroon)," Parasites and Vectors, vol. 4, no. 1, p. 181, 2011.

[27] P. J. Krezanoski, D. R. Bangsberg, and A. C. Tsai, "Quantifying bias in measuring insecticide-treated bednet use: meta-analysis of self-reported vs objectively measured adherence," Journal of Global Health, vol. 8, no. 1, article 010411, 2018.

[28] Y. Geissbühler, K. Kannady, P. P. Chaki et al., "Microbial larvicide application by a large-scale, community-based program reduces malaria infection prevalence in urban Dar Es Salaam, Tanzania," PLoS One, vol. 4, no. 3, article e5107, 2009.

[29] M. Maheu-Giroux and M. C. Castro, "Impact of communitybased larviciding on the prevalence of malaria infection in Dar es Salaam, Tanzania," PLoS One, vol. 8, no. 8, article e71638, 2013.

[30] F. Chukwuneke, C. Ezeonu, B. Onyire, and P. O. Ezeonu, "Culture and biomedical care in Africa: the influence of culture on biomedical care in a traditional African society, Nigeria, West Africa," Nigerian Journal of Medicine, vol. 21, p. 3, 2012.

[31] D. S. Nsagha, A. L. Njunda, H. L. F. Kamga et al., "Knowledge and practices relating to malaria in Ndu community of Cameroon: signs and symptoms, causes and prevention," Journal of Public Health and Epidemiology, vol. 3, p. 8, 2011.

[32] V. Makoge, H. Maat, N. Edward, and J. Emery, "Knowledge, attitudes and practices towards malaria in Mbonge and Kumba sub-divisions in Cameroon," International Journal of TROPICAL DISEASE \& Health, vol. 15, no. 2, pp. 1-13, 2016.

[33] E. N. Nga, E. C. Eboumbou Moukoko, N. J. Pierre, M. E. R. Ewoudou, and E. M. Mpondo, "Évaluation pharmacotechnique des molécules antipaludiques du marché légal et du marché illicite à Yaoundé: Cas de l'Arteméther - Luméfantrine 20/120," Health Sciences Diseases, vol. 16, no. 2, pp. 1-5, 2015.
[34] A. Talipouo, C. S. Ngadjeu, P. Doumbe-Belisse et al., "Malaria prevention in the city of Yaoundé: knowledge and practices of urban dwellers," Malaria Journal, vol. 18, no. 1, p. 167, 2019.

[35] A. Mills, C. Goodman, G. Gree, A. Unwin, W. Brieger, and S. Meek, "Medicine sellers and malaria treatment in subSaharan Africa: what do they do and how can their practice be improved?," The American Journal of Tropical Medicine and Hygiene, vol. 77, no. 6, pp. 203-2018, 2007.

[36] A. A. Adedotun, O. A. Morenikeji, and A. B. Odaibo, "Knowledge, attitudes and practices about malaria in an urban community in south-western Nigeria," Journal of Vector Borne Diseases, vol. 47, no. 3, 2010. 